\title{
Biotechnology
}

\section{Production, Properties and Transit of Copper-Pectic Gel Particles through an Artificial Gastroenteric Environment}

\author{
Anatoly A. Shubakov, $\mathrm{PhD}^{1,2}$; Elena A. Mikhailova ${ }^{1 *}$ \\ ${ }^{I}$ Institute of Physiology of Komi Science Centre of the Ural Branch of the RAS, \\ FRC Komi SC UB RAS \\ ${ }^{2}$ Institute of Biology of Komi Science Centre of the Ural Branch of the RAS, \\ FRC Komi SC UB RAS \\ Syktyvkar, Komi Republic, the Russian Federation
}

\begin{abstract}
Spherical copper-pectic gel particles (CuPGPs) were obtained from aqueous solutions of commercial apple pectin (AP) AU701 (2\%, $4 \%)$ in the presence of copper ions $\left(\mathrm{CuCl}_{2}, 1 \%-10 \%\right)$, and their morphological (diameter) and structural-mechanical (density) characteristics were studied. It was found that with an increase in the concentration of AP from $2 \%$ to $4 \%$, the diameter of dry gel particles at all tested concentrations of copper chloride (1-10\%) increased from $0.64-0.76 \mathrm{~mm}(2 \%$ AP) to $0.87-0.94 \mathrm{~mm}$ ( $4 \% \mathrm{AP})$, and that the density of dry gel particles with an increase in the concentration of AP also increased from 1.27-1.48 mg/ $\mathrm{mm}^{3}(2 \% \mathrm{AP})$ to $1.42-1.55 \mathrm{mg} / \mathrm{mm}^{3}(4 \% \mathrm{AP})$. The swelling and degradation of the obtained CuPGPs in an artificial gastroenteric environment was studied. It has been established that the CuPGPs based on $4 \%$ AP with $10 \% \mathrm{CuCl}_{2}$ have the highest degree of swelling in the acidic environment of the intestinal gastric fluid (SGF). CuPGPs, depending on the concentration of AP and copper ions, are degraded in different parts of the intestine - in simulated intestinal fluid (SIF) or simulated colonic fluid (SCF). (International Journal of Biomedicine. 2020;10(4):421-423.)
\end{abstract}

Key Words: apple pectin $\bullet$ cross-linking agents $\bullet$ copper ions $\bullet$ gel particles $\bullet$ gastroentestinal tract

\section{Abbreviations}

AP, apple pectin; CuPGPs, copper-pectic gel particles; CaPGPs, calcium-pectic gel particles; GIT, gastroentestinal tract; SGF, simulated gastric fluid; SIF, simulated intestinal fluid; SCF, simulated colonic fluid.

\section{Introduction}

Pectins are natural biodegradable polysaccharides that, due to their high physiological activity and ability to form gels, are widely used in the food and pharmaceutical industries..$^{(1)}$ The main commercial pectins with high gel-forming ability are apple and citrus pectins. ${ }^{(2,3)}$ The widespread use of pectins is based on their ability to form gels. High methyl-esterified pectins (HMEPs) form gels with sugar and acid, low methyl-

"Corresponding author: Elena A. Mikhailova, Institute of Physiology of Komi Science Centre of the Ural Branch of the RAS, FRC Komi SC UB RAS. Syktyvkar, Russia. E-mail: elkina@physiol. komisc.ru esterified pectins (LMEPs) quickly form gels in the presence of divalent metal ions (calcium, etc.). ${ }^{(4,5)}$

Pectin, a naturally occurring component of human food, slows down the rate of digestion, resulting in less food absorption. Due to its high water-binding capacity, pectin gives a feeling of fullness, which reduces food intake. These properties of pectin are used in the treatment of binge eating disorders. $^{(6)}$

LMEPs form gels in the presence of divalent cations, with calcium ions being the most commonly used as a crosslinking agent. Modern articles and reviews have focused specifically on this type of gel, which is often referred to as "calcium gel." (3,7) Copper ions can be a promising crosslinking agent in the preparation of pectic gel particles. Copper 
is one of the most important essential trace elements that are essential for the normal life of plants and animals, including humans. It is a biogenic element, a permanent component of the human body. The main biological role of copper is that it is a component of many enzymes with redox activity. ${ }^{(8)}$ Using copper ions as a cross-linking agent, the gelation of HMEPs, ${ }^{(9)}$ $\mathrm{Cu}$-alginate ${ }^{(10)}$ has been previously studied. The study of the gelation of LMEP (AP) using copper ions as a cross-linking agent is also relevant.

The aim of our work was to obtain and study the properties of CuPGPs, and to study the swelling and degradation of CuPGPs during incubation in the artificial gastroenteric environment.

\section{Materials and Methods}

\section{Formation of dry CuPGPs and study of morphological and structural-mechanical properties}

Pectic gel particles were obtained on the basis of commercial AP AU701 (AP, Herbstreith \& Fox KG, Germany) using copper ions as a cross-linking agent by the method of ionotropic gelling, which was described in earlier works. ${ }^{(4,5)}$ CuPGPs were obtained at AP concentrations of $2 \%$ and $4 \%$ and $\mathrm{CuCl}_{2}$ concentrations of $1 \%-10 \%$. Certain weighed portions of pectins were dissolved in corresponding volumes of distilled water by slow stirring with a magnetic stirrer MM-5 (Russia) for 2-5 hours at room temperature until complete dissolution.

Gel particles of spherical shape were prepared by dropby-drop injection of a pectin solution from a syringe through a needle with a hole diameter of $0.7 \mathrm{~mm}$ on the distance of 4-5 $\mathrm{cm}$ in the slowly stirred copper chloride solution and further stirring for $20 \mathrm{~min}$ at room temperature. The resulting gel particles were then washed three times in distilled water with stirring for 5 minutes and dried for $10-14 \mathrm{~h}$ at $37^{\circ} \mathrm{C}$.

Further, the diameter, surface area, volume, and density of CuPGPs were determined using an optical microscope (Altami, Russia) with a camera and an image analysis program (ImageJ 1.46r program, National Institutes of Health, USA). For calibration, a linear scale was used; one pixel corresponded to $0.024 \mathrm{~mm}$.

Study of swelling and degradation of CuPGPs in simulated gastrointestinal media

The swelling and degradation of CuPGPs were studied under conditions simulating the gastrointestinal environment: for these purposes, the simulated gastric fluid (SGF solution, $\mathrm{pH}$ 1.25), simulated intestinal fluid (SIF solution, $\mathrm{pH} 7.0$ ) and simulated colonic fluid (SCF solution, $\mathrm{pH} 7.0$ ), as described previously. ${ }^{(11)}$

To determine swelling and degradation, dry CuPGPs (1-2 $\mathrm{mg})$ were placed in Petri dishes (diameter $3.5 \mathrm{~cm}$ ) and subsequently incubated in $3 \mathrm{ml}$ of SGF (2h), SIF (4h) and SCF solutions with shaking in a shaker (Titramax 1000, Heidolph, Germany) at $100 \mathrm{rpm}$ and $37^{\circ} \mathrm{C}$. The diameter, surface area, volume and density of 100 randomly selected gel particles were measured as described above after certain time intervals. The experiments were performed in triplicate. The degree of gel swelling $(\mathrm{SD}, \%)$ was determined by the formula ${ }^{(12)}$ : $\mathrm{SD}=$ $\left(\mathrm{D}_{1}-\mathrm{D}_{0}\right) / \mathrm{D}_{0} \times 100 \%$, where $\mathrm{D}_{1}$ - diameter of the particles $(\mathrm{mm})$ after a certain incubation time in the medium, $\mathrm{D}_{0}-$ initial diameter of the particles $(\mathrm{mm})$.

The statistical analysis was performed using the statistical software BioStat (version 4.03) and Microsoft Office Excel 2007.

\section{Results and Discussion}

The gel-forming properties of pectins depend on the degree of methyl esterification of carboxyl groups of galacturonic acid residues, on the structure of pectin side chains, pectin concentration, $\mathrm{pH}$, concentration of metal ions, ionic strength of solution, and temperature. ${ }^{(3,13)}$ Spherical pectic gel particles are formed as a result of the gelation, in which intermolecular cross-links arise between divalent metal ions and negatively charged carboxyl groups of pectin macromolecules. ${ }^{(14,15)}$

The $2 \%$ and $4 \%$ aqueous solutions of $\mathrm{AP}$ in the presence of copper ions $\left(\mathrm{CuCl}_{2}, 1-10 \%\right)$ yield the spherical CuPGPs, which were subjected to determine their morphological and structural-mechanical characteristics (diameter, density).

It was found that with an increase in the concentration of AP from $2 \%$ to $4 \%$, the diameter of dry gel particles at all tested concentrations of $\mathrm{CuCl}_{2}$ increased from $0.64-0.76 \mathrm{~mm}$ ( $2 \% \mathrm{AP})$ to $0.87-0.94 \mathrm{~mm}(4 \% \mathrm{AP})$ (Table 1$)$.

\section{Table 1.}

Diameter of dry copper-pectic gel particles (M $\pm S D, m m)$

\begin{tabular}{|c|c|c|c|c|c|c|}
\hline \multirow{2}{*}{$\begin{array}{c}\text { AP } \\
\text { concent- } \\
\text { ration }\end{array}$} & \multicolumn{5}{|c|}{$\mathrm{CuCl}_{2}$ concentration } \\
\cline { 2 - 7 } & $1 \%$ & $2 \%$ & $3 \%$ & $4 \%$ & $5 \%$ & $10 \%$ \\
\hline $2 \%$ & $\begin{array}{c}0.64 \\
\pm 0.03\end{array}$ & $\begin{array}{c}0.65 \\
\pm 0.04\end{array}$ & $\begin{array}{c}0.70 \\
\pm 0.04\end{array}$ & $\begin{array}{c}0.72 \\
\pm 0.05\end{array}$ & $\begin{array}{c}0.75 \\
\pm 0.03\end{array}$ & $\begin{array}{c}0.76 \\
\pm 0.04\end{array}$ \\
\hline $4 \%$ & $\begin{array}{c}0.87 \\
\pm 0.03\end{array}$ & $\begin{array}{c}0.87 \\
\pm 0.04\end{array}$ & $\begin{array}{c}0.88 \\
\pm 0.04\end{array}$ & $\begin{array}{c}0.90 \\
\pm 0.02\end{array}$ & $\begin{array}{c}0.93 \\
\pm 0.03\end{array}$ & $\begin{array}{c}0.94 \\
\pm 0.04\end{array}$ \\
\hline
\end{tabular}

The density of dry gel particles with an increase in the concentration of $\mathrm{AP}$ at all tested concentrations of $\mathrm{CuCl}_{2}$ also increased from $1.27-1.48 \mathrm{mg} / \mathrm{mm}^{3}$ (2\% AMP) to $1.42-1.55$ $\mathrm{mg} / \mathrm{mm}^{3}$ (4\% AP) (Table 2).

Table 2.

Density of dry copper-pectic gel particles ( $\left.M \pm S D, \mathrm{mg} / \mathrm{mm}^{3}\right)$

\begin{tabular}{|c|c|c|c|c|c|c|}
\hline \multirow{2}{*}{$\begin{array}{c}\text { AP } \\
\text { concent- } \\
\text { ration }\end{array}$} & \multicolumn{6}{|c|}{$\mathrm{CuCl}_{2}$ concentration } \\
\cline { 2 - 7 } & $1 \%$ & $2 \%$ & $3 \%$ & $4 \%$ & $5 \%$ & $10 \%$ \\
\hline $2 \%$ & $\begin{array}{c}1.27 \\
\pm 0.18\end{array}$ & $\begin{array}{c}1.35 \\
\pm 0.13\end{array}$ & $\begin{array}{c}1.36 \\
\pm 0.25\end{array}$ & $\begin{array}{c}1.41 \\
\pm 0.28\end{array}$ & $\begin{array}{c}1.44 \\
\pm 0.19\end{array}$ & $\begin{array}{c}1.48 \\
\pm 0.22\end{array}$ \\
\hline $4 \%$ & $\begin{array}{c}1.42 \\
\pm 0.14\end{array}$ & $\begin{array}{c}1.45 \\
\pm 0.12\end{array}$ & $\begin{array}{c}1.48 \\
\pm 0.10\end{array}$ & $\begin{array}{c}1.50 \\
\pm 0.10\end{array}$ & $\begin{array}{c}1.52 \\
\pm 0.12\end{array}$ & $\begin{array}{c}1.55 \\
\pm 0.18\end{array}$ \\
\hline
\end{tabular}

The previously obtained dry CaPGPs based on 3\% AP using calcium ions $\left(0.34 \mathrm{M} \mathrm{CaCl}_{2}\right)$ as a cross-linking agent have a larger diameter of $1.21 \pm 0.05 \mathrm{~mm}$ and about three times 
smaller density ${ }^{(3)}-0.51 \pm 0.05 \mathrm{mg} / \mathrm{mm}^{3}$ - than CuPGPs. Seslija et al., ${ }^{(9)}$ when comparing a number of divalent cations as crosslinking agents, found that $\mathrm{Cu}^{2+}$ ions bind pectin most strongly and $\mathrm{Ca}^{2+}$ ions weakly. Probably for this reason, in our studies, copper ions formed smaller, but denser, gel particles from AP than calcium ions.

The swelling and degradation of the obtained CuPGPs in an artificial gastroenteric environment was studied. Gel particles formed from $2 \%$ AP with $1 \%-5 \% \mathrm{CuCl}_{2}$ swelled in a simulated gastric fluid SGF by $90 \%-150 \%$ and degraded in a simulated intestinal fluid SIF during the first 30 minutes of incubation in it. Gel particles obtained from 2\% and 4\% AP with $10 \% \mathrm{CuCl}_{2}$ swelled in SGF by $161 \%-173 \%$ and then, depending on the concentration of pectin, degraded in SIF or SCF (Fig.1).

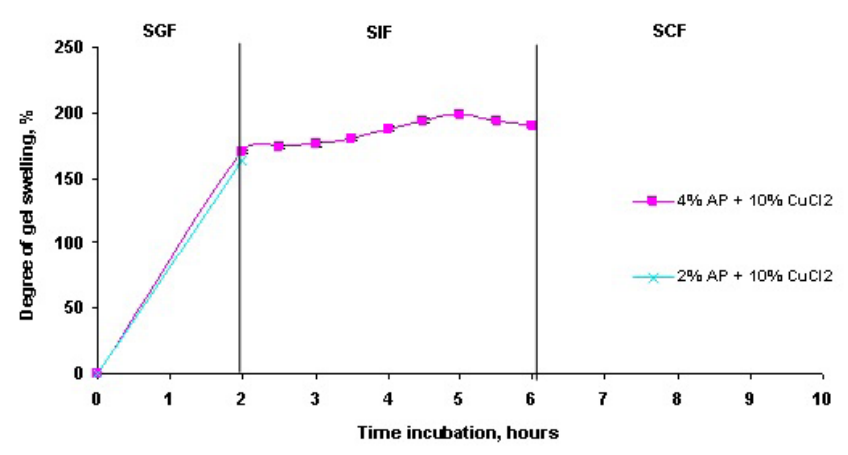

Fig.1. Swelling and degradation of CuPGPs formed from AP $(2 \%$ and $4 \%)$ and copper ions $(10 \% \mathrm{CuCl})$ in an artificial GIT.

Gel particles formed from 2\% AP with $10 \% \mathrm{CuCl}_{2}$ degraded in SIF during the first 30 minutes of incubation in it. Gel particles obtained on the basis of $4 \% \mathrm{AP}$ with $10 \% \mathrm{CuCl}_{2}$ are more stable and degraded in SCF in the first minutes of incubation in it.

Previously, we found that CaPGPs formed from 3\% AP using calcium ions as a cross-linking agent completely degrade in a simulated fluid of the small intestine after $3 \mathrm{~h}$ of incubation in it. ${ }^{(3)}$

Thus, the gel particles formed on the basis of $4 \% \mathrm{AP}$ with $10 \% \mathrm{CuCl}_{2}$ as a cross-linking agent have the greatest degree of swelling in the acidic environment of the stomach. CuPGPs, depending on the concentration of AP and copper ions, are degraded in different parts of the intestine - in SIF or SCF. Copper ions as cross-linking agents form smaller, but denser gel particles from AP than calcium ions.

\section{Competing Interests}

The authors declare that they have no competing interests.

\section{Sources of Funding}

The work was performed on the theme of research work (State registration number AAAA-A17-117012310147-8).

\section{References}

1. Ovodov YuS. [Current information about pectin substances]. Bioorg Khim. 2009 May-Jun;35(3):293-310. doi: 10.1134/s1068162009030017. [Article in Russian].

2. Thakur BR, Singh RK, Handa AK. Chemistry and uses of pectin--a review. Crit Rev Food Sci Nutr. 1997 Feb;37(1):4773. doi: 10.1080/10408399709527767.

3. Shubakov AA, Mikhailova EA, Prosheva VI, Belyy VA. Swelling and degradation of calcium-pectic gel particles made of pectins of Silene vulgaris and Lemna minor callus cultures at different concentrations of pectinase in an artificial colon environment. International Journal of Biomedicine. 2018;8(1):60-64. doi: 10.21103/Article8(1)_OA10

4. Sriamornsak P. Effect of calcium concentration, hardening agent and drying condition on release characteristics of oral proteins from calcium pectinate gel beads. Eur J Pharm Sci. 1999 Jul;8(3):221-7. doi: 10.1016/s0928-0987(99)00010-x.

5. Sriamornsak P, Nunthanid J. Calcium pectinate gel beads for controlled release drug delivery: I. Preparation and in vitro release studies. Int J Pharm. 1998;160:207-212. doi: PII S0378-5173(97)00310-4

6. Tyagi V, Sharma PK, Malviya R. Pectins and their role in food and pharmaceutical industry: A review. J Chronother Drug Deliv. 2015;6(3):65-77.

7. Fraeye I, Duvetter T, Doungla E, Van Loey A, Hendrickx $\mathrm{M}$. Fine-tuning the properties of pectin-calcium gels by control of pectin fine structure, gel composition and environmental conditions. Trends Food Sci Tech. 2010;21(5):219-228. doi: 10/1016/J.TIFS.2010.02.001

8. Williams RJP. Missing information in bio-inorganic chemistry. Coord Chem Rev. 1987;79(3):175-193. doi: 10.1016/0010-8545(87)80002-4

9. Seslija S, Veljovic D, Krusic MK, Stevanovic J, Velickovic S, Popovic I. Cross-linking of highly methoxylated pectin with copper: the specific anion influence. New J. Chem. 2016;40:1618-1625. doi: 10.1039/C5NJ0332A

10. Rodrigues JR, Lagoa R. Copper ions binding in $\mathrm{Cu}$ alginate gelation. J Carbohydr Chem. 2006;25:219-232. doi: 10.1080/07328300600732956

11. Gebara C, Chaves KS, Ribeiro MCE, Souza FN, Grosso CRF, Gigante ML. Viability of Lactobacillus acidophilus La5 in pectin-whey protein microparticles during exposure to simulated gastrointestinal conditions. Food Res Int. 2013;51:872-878. doi: 10.1016/j.foodres.2013.02.008

12. Oliveira GF, Ferrari PC, Carvalho LQ, Evangelista RC. Chitosan-pectin multiparticulate systems associated with enteric polymers for colonic drug delivery. Carbohydr Polym. 2010;82(3):1004-1009. doi: 10.1016/j.carbpol.2010.06.041

13. Matveyev YuI. [A method of calculating gelation parameters in aqueous solutions of biopolymers]. Vysokomolekulyarnye Soedinenija. Seriya B. 2003;45(5):841-850. [Article in Russian]. 14. Mikhailova EA, Melekhin AK, Belyy VA, Shubakov AA. Stability of hyaluronan-pectic gel particles in the conditions of the artificial gastrointestinal environment. International Journal of Biomedicine. 2017;7(4):310-314. doi: 10.21103/ Article7(4) OA8

15. Sriamornsak P, Kennedy RA. Swelling and diffusion studies of calcium polysaccharide gels intended for film coating. Int J Pharm. 2008 Jun 24;358(1-2):205-213. doi: 10.1016/j.ijpharm.2008.03.009. 